\title{
Disease activity in COPD: time to make imaging biomarkers a PET project?
}

\author{
Stephen Milne $\mathbb{Q}^{1,2,3}$, Rachel L. Eddy $\mathbb{1}^{1,2}$ and Don D. $\operatorname{Sin}^{1,2}$
}

${ }^{1}$ Centre for Heart Lung Innovation, St Paul's Hospital, University of British Columbia, Vancouver, BC, Canada. ${ }^{2}$ Division of Respiratory Medicine, University of British Columbia, Vancouver, BC, Canada. ${ }^{3}$ Sydney Medical School, University of Sydney, Sydney, NSW, Australia.

Corresponding author: Stephen Milne (stephen.milne@hli.ubc.ca)

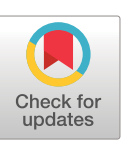

This version is distributed under the terms of the Creative Commons Attribution NonCommercial Licence 4.0. For commercial reproduction rights and permissions contact permissions@ersnet.org

Received: 5 July 2021 Accepted: 6 July 2021

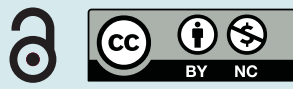

Shareable abstract (@ERSpublications)

FDG uptake on PET/CT is a potential biomarker of pulmonary inflammation in COPD and may reflect disease activity, but does it have the characteristics of a "good" biomarker? https://bit.ly/3AXheEZ

Cite this article as: Milne S, Eddy RL, Sin DD. Disease activity in COPD: time to make imaging biomarkers a PET project? ERJ Open Res 2021; 7: 00445-2021 [DOI: 10.1183/23120541.00445-2021].

COPD is a complex and markedly heterogeneous condition for which a one-size-fits-all approach to treatment is clearly unsatisfactory. Instead, COPD is well suited to a "precision medicine" approach whereby treatments are targeted towards patients who will likely gain the most benefit [1]. Central to the precision medicine paradigm is the use of biomarkers, which are defined by the US National Institutes of Health (NIH) as objectively measured characteristics that indicate normal biological processes, pathogenic processes, or pharmacologic responses to therapeutic interventions [2]. Biomarkers can be categorised based on their function or intent, such as susceptibility, diagnosis, prognosis, or prediction of treatment responses [3]. Plasma fibrinogen is currently the only COPD biomarker approved by the US Food and Drug Administration (FDA) Biomarker Qualification Program [4], and is used for the enrichment of clinical trial cohorts with participants at increased risk of moderate-severe acute exacerbations of COPD [5-7].

In this issue of ERJ Open Research, VASs et al. [8] investigated ${ }^{18} \mathrm{~F}$-fluorodeoxyglucose positron emission tomography paired with computed tomography (FDG PET/CT) as a potential biomarker of pulmonary inflammation in COPD. FDG is a glucose analogue that is taken up by highly metabolically active cells including malignant and inflammatory cells. By pooling participants from two previously published research cohorts $[9,10]$, the investigators found that participants with smoking-related COPD, alpha-1 antitrypsin deficiency-associated COPD, and smokers with normal spirometry had significantly greater pulmonary FDG uptake than never-smokers, but were not distinguishable from each other. The differences were significant in the upper and middle, but not lower lung regions, although FDG uptake was not dependent on lung parenchymal changes on CT. This discrepancy may reflect differences in lung inflammation across lung zones that are distinct from structural changes or could be due to technical issues, such as motion artefact in the lower zones, rather than true regional differences in inflammation. While the regional differences warrant further investigation to distinguish true disease underpinnings from technical limitations, the authors concluded that FDG-PET/CT may be useful to both quantify and visualise pulmonary inflammation in COPD [8].

Even though the finding that pulmonary FDG uptake is increased in COPD is not new [11, 12], the present study [8] is the largest of its kind and made a number of observations that are important when considering its utility as a potential biomarker. The first was that current smokers with normal spirometry had just as much lung inflammation as participants with definite COPD. Previous studies suggest that the extent of inflammatory activation in response to cigarette smoke exposure may indicate susceptibility to developing COPD [13]. Since only a minority of smokers will progress to definite COPD [14], a susceptibility biomarker could allow targeted preventive strategies although this would require large, longitudinal studies to establish. The second was that pulmonary FDG uptake in COPD was stable over time. Imaging 
performed 4 months apart showed a mean difference of only 3.2\% and a low within-subject coefficient of variation of $7.7 \%$. Interestingly, and unlike the clinically stable participants, those who experienced an AECOPD during the follow-up period had a small but definite increase in pulmonary FDG uptake on repeat imaging, suggesting that FDG uptake may track with exacerbations. Finally, pulmonary FDG uptake was positively correlated with a number of peripheral blood inflammatory markers, most notably plasma fibrinogen, which was independent of current smoking status and forced expiratory volume in $1 \mathrm{~s}\left(\mathrm{FEV}_{1}\right) \%$ predicted.

Together, these observations suggest that pulmonary FDG uptake may reflect "disease activity”, a concept that is distinct from "disease severity" (which can be measured by FEV 1 or BODE (body mass index, airflow obstruction, dyspnoea, exercise capacity) index) and that is well understood in other chronic diseases such as inflammatory bowel disease [15] and rheumatoid arthritis [16], but has been difficult to quantify in COPD [17]. Having a biomarker of disease activity would be a welcome tool in the precision medicine arsenal, since it may allow risk stratification, prognostication, targeted treatment, or treatment response monitoring.

This imaging study [8] is a reminder that biomarker candidates need not be limited to blood measurements or genetic markers. Indeed, CT and magnetic resonance imaging (MRI) have been extensively considered for biomarker development in COPD (table 1). CT has been the workhorse modality for evaluation of COPD using both qualitative [18] and quantitative [19] approaches. Quantitative CT methods have generated a wealth of candidate biomarkers that probe structural alterations in the lung parenchyma, such as the lung density measurements reported in the current study [8], as well as airways and pulmonary vessels. Paired inspiratory-expiratory CT may also be analysed for indirect functional biomarkers [20], such as small airways disease or gas trapping [21, 22], and lung biomechanics [23]. In contrast, MRI using inhaled hyperpolarised gases $\left({ }^{3} \mathrm{He}\right.$ or $\left.{ }^{129} \mathrm{Xe}\right)$ provides direct functional information in the form of pulmonary ventilation distribution and gas exchange [24] that are highly abnormal and regionally heterogeneous in patients with COPD [25, 26]. An important advantage of imaging over other approaches to biomarker discovery is the ability to capture regional heterogeneity in lung structure, function and physiology that is characteristic of COPD. Numerous multimodality imaging measurements, whether PET, CT or MRI, have immense potential as biomarkers to enable precision medicine in COPD, yet still require rigorous evaluation to meet NIH and FDA biomarker criteria.

When considering whether to pursue a novel potential biomarker, consideration must be given to what makes a "good" biomarker [3]. For example: there should be biological plausibility with a strong, consistent, and independent relationship between the biomarker and the disease; the biomarker test should be robust and accurate, and its association with the disease or treatment outcomes should be free from confounding influences unrelated to the disease itself; "monitoring” biomarkers should be directly related to a change in the clinical state; "predictive" biomarkers should be able to predict treatment effects that are clinical meaningful; and all biomarkers should be relatively simple, accessible, and easily interpretable in order to facilitate translation from research to practice.

So, might pulmonary FDG uptake on PET/CT be a "good" imaging biomarker in COPD? The present study [8] begins to build a case for this by demonstrating repeatability over time in stable COPD patients, and changes that may reflect clinical state (i.e. recent exacerbations). However, several questions remain

TABLE 1 PET, CT and MRI: summary for potential COPD biomarkers

\begin{tabular}{|c|c|c|c|c|c|c|}
\hline Modality & Type & Measurement & Potential biomarker of & Radiation & Cost & Time \\
\hline PET & Functional ${ }^{18} \mathrm{~F}-\mathrm{FDG}$ & $\begin{array}{l}\text { Lung FDG uptake } \\
\text { Large vessel FDG uptake }\end{array}$ & $\begin{array}{l}\text { Pulmonary inflammation } \\
\text { Risk of cardiovascular events }\end{array}$ & +++ & ++ & +++ \\
\hline \multirow[t]{2}{*}{ CT } & $\begin{array}{l}\text { Structural } \\
\text { Insp only }\end{array}$ & $\begin{array}{l}\text { Lung density } \\
\text { Airway structure } \\
\text { Vascular pruning }\end{array}$ & $\begin{array}{l}\text { Emphysema, } \mathrm{AECOPD} \text { risk, } \mathrm{FEV}_{1} \text { decline } \\
\text { COPD risk, } \mathrm{FEV} \mathrm{V}_{1} \text { decline } \\
\text { Mortality risk }\end{array}$ & + & + & + \\
\hline & $\begin{array}{l}\text { Functional } \\
\text { Insp/Exp }\end{array}$ & $\begin{array}{l}\text { Low density on exp } \\
\text { Deformation on image registration }\end{array}$ & $\begin{array}{l}\text { Small airways disease/gas trapping } \\
\text { Biomechanics }\end{array}$ & ++ & + & + \\
\hline MRI & $\begin{array}{l}\text { Functional } \\
{ }^{3} \mathrm{He} /{ }^{129} \mathrm{Xe}\end{array}$ & $\begin{array}{l}\text { Ventilation defect percent } \\
\text { Dissolved phase }\end{array}$ & $\begin{array}{l}\text { Ventilation heterogeneity } \\
\text { Gas exchange }\end{array}$ & - & +++ & + \\
\hline
\end{tabular}

PET: positron emission tomography; $\mathrm{CT}$ : computed tomography; MRI: magnetic resonance imaging; Exp: expiratory; Insp: inspiratory; FDG: fluorodeoxyglucose; $\mathrm{FEV}_{1}$ : forced expiratory volume in $1 \mathrm{~s}$; AECOPD: acute exacerbation of COPD. 
unanswered in order to establish its utility as a biomarker. First, does the large variability in FDG uptake among COPD participants reflect true variability in disease activity between patients? This could be answered in longitudinal studies that relate lung FDG uptake to clinical indicators of disease activity, in studies that monitor the FDG response to anti-inflammatory treatments such as inhaled corticosteroids, or even using a more novel approach of relating FDG uptake to regional lung inflammation sampled via bronchoscopy. Secondly, does the strong effect of current smoking on FDG uptake indicate that smoking incites or enhances disease activity, or does it merely confound the relationship? This would need to be determined in order to make both within- and between-subject comparisons. Finally, would the ionising radiation, long examination time, and relative inaccessibility of PET/CT ultimately limit its viability as a biomarker outside the research setting?

Nevertheless, the study by VAss et al. [8] is an important advancement for biomarker discovery and development in COPD. The association between pulmonary FDG uptake and disease activity deserves further investigation, and the qualities of a "good" biomarker should be taken into consideration when designing future studies.

Provenance: Commissioned article, peer reviewed.

Conflict of interest: S. Milne has nothing to disclose. R.L. Eddy receives consulting fees from VIDA Diagnostics Inc., outside the current work. D.D. Sin has received research grants from GlaxoSmithKline, and personal honoraria for speaking engagements from GlaxoSmithKline, Novartis and Boehringer Ingelheim, outside the current work.

Support statement: S. Milne is supported by the MITACS Accelerate Program. R.L. Eddy is supported by the Natural Sciences and Engineering Research Council of Canada and the Michael Smith Foundation for Health Research. D.D. Sin is a Tier 1 Canada Research Chair in COPD and the De Lazzari Family Chair at HLI.

\section{References}

1 Leung JM, Obeidat M, Sadatsafavi M, et al. Introduction to precision medicine in COPD. Eur Respir J 2019; 53: 1802460

2 Biomarkers Definition Working Group. Biomarkers and surrogate endpoints: preferred definitions and conceptual framework. Clin Pharmacol Ther 2001; 69: 89-95.

3 Milne S, Sin DD. Biomarkers in chronic obstructive pulmonary disease: the gateway to precision medicine. Clin Chest Med 2020; 41: 383-394.

4 United States Food and Drug Administration. Biomarker Qualification Submissions [online resource]. www.fda.gov/ drugs/cder-biomarker-qualification-program/biomarker-qualification-submissions Date last accessed: 17 June 2021.

5 Groenewegen KH, Postma DS, Hop WCJ, et al. Increased systemic inflammation is a risk factor for COPD exacerbations. Chest 2008; 133: 350-357.

6 Miller BE, Tal-Singer R, Rennard SI, et al. Plasma fibrinogen qualification as a drug development tool in chronic obstructive pulmonary disease. Perspective of the Chronic Obstructive Pulmonary Disease Biomarker Qualification Consortium. Am J Respir Crit Care Med 2016; 193: 607-613.

7 Mannino DM, Tal-Singer R, Lomas DA, et al. Plasma fibrinogen as a biomarker for mortality and hospitalized exacerbations in people with COPD. Chronic Obstr Pulm Dis 2015; 2: 23-34.

8 Vass L, Fisk M, Cheriyan J, et al. Quantitative ${ }^{18} \mathrm{~F}$-fluorodeoxyglucose positron emission tomography/ computed tomography to assess pulmonary inflammation in COPD. ERJ Open Res 2021; 7: 00699-2020.

9 Fisk M, Mohan D, Cheriyan J, et al. Evaluation of losmapimod in patients with chronic obstructive pulmonary disease (COPD) with systemic inflammation stratified using fibrinogen ('EVOLUTION'): Rationale and protocol. Artery Research 2014; 8: 24-34.

10 Fisk M, Cheriyan J, Mohan D, et al. Vascular inflammation and aortic stiffness: potential mechanisms of increased vascular risk in chronic obstructive pulmonary disease. Respir Res 2018; 19: 100.

11 Jones HA, Marino PS, Shakur BH, et al. In vivo assessment of lung inflammatory cell activity in patients with COPD and asthma. Eur Respir J 2003; 21: 567-573.

12 Subramanian DR, Jenkins L, Edgar R, et al. Assessment of pulmonary neutrophilic inflammation in emphysema by quantitative positron emission tomography. Am J Respir Crit Care Med 2012; 186: 1125-1132.

13 Hoonhorst SJM, Timens W, Koenderman L, et al. Increased activation of blood neutrophils after cigarette smoking in young individuals susceptible to COPD. Respir Res 2014; 15: 121.

14 Lundbäck B, Lindberg A, Lindström M, et al. Not 15 but $50 \%$ of smokers develop COPD? - Report from the obstructive lung disease in Northern Sweden Studies. Respir Med 2003; 97: 115-122.

15 Sostegni R, Daperno M, Scaglione N, et al. Crohn's disease: monitoring disease activity. Aliment Pharmacol Ther 2003; 17: 11-17. 
Anderson J, Caplan L, Yazdany J, et al. Rheumatoid arthritis disease activity measures: American College of Rheumatology recommendations for use in clinical practice. Arthritis Care Res 2012; 64: 640-647.

17 Celli B, Locantore N, Yates JC, et al. Markers of disease activity in COPD: an 8-year mortality study in the ECLIPSE cohort. Eur Respir J 2021; 57: 2001339.

18 Lynch DA, Austin JH, Hogg JC, et al. CT-definable subtypes of chronic obstructive pulmonary disease: a statement of the Fleischner Society. Radiology 2015; 277: 192-205.

19 Lynch DA, Al-Qaisi MA. Quantitative computed tomography in chronic obstructive pulmonary disease. J Thorac Imaging 2013; 28: 284-290.

20 Bodduluri S, Bhatt SP, Reinhardt JM. Computed tomography image matching in chronic obstructive pulmonary disease. Crit Rev Biomed Eng 2016; 44: 411-425.

21 Galbán CJ, Han MK, Boes JL, et al. Computed tomography-based biomarker provides unique signature for diagnosis of COPD phenotypes and disease progression. Nat Med 2012; 18: 1711-1715.

22 Kirby $M$, Yin Y, Tschirren J, et al. A novel method of estimating small airway disease using inspiratoryto-expiratory computed tomography. Respiration 2017; 94: 336-345.

23 Reinhardt JM, Ding K, Cao K, et al. Registration-based estimates of local lung tissue expansion compared to xenon CT measures of specific ventilation. Med Image Anal 2008; 12: 752-763.

24 Stewart NJ, Smith LJ, Chan H-F, et al. Lung MRI with hyperpolarised gases: current and future clinical perspectives. Br J Radiol 2021; in press [https://doi.org/10.1259/bjr.20210207].

25 Wang Z, Bier EA, Swaminathan A, et al. Diverse cardiopulmonary diseases are associated with distinct xenon magnetic resonance imaging signatures. Eur Respir J 2019; 54: 1900831.

26 Mummy DG, Coleman EM, Wang Z, et al. Regional gas exchange measured by ${ }^{129}$ Xe magnetic resonance imaging before and after combination bronchodilators treatment in chronic obstructive pulmonary disease. J Magn Reson Imaging 2021; 54: 964-974. 